\title{
El proceso de resemantización de los términos parche y chimba en el parlache*
}

\author{
Luz Stella Castañeda* \\ José Ignacio Henao ${ }^{* * *}$ \\ Sergio Alonso Lopera ${ }^{* * *}$
}

\section{Resumen}

En este artículo se presenta el análisis del proceso de resemantización y recategorización de las piezas lexicales parche y chimba, las cuales forman parte del parlache, variedad argótica del español colombiano. Basados en el Diccionario de uso de parlache (2015) los resultados indican que la palabra parche adquiere unos nuevos significados como sustantivo, verbo pronominal y forma varias locuciones. Chimba cambia de sustantivo a verbo, se usa la parasíntesis para la creación léxica, en fórmulas rutinarias y locuciones verbales.

Palabras clave: resemantización, recategorización, parche, chimba, parlache.

\section{The resemantization process of the words parche and chimba in parlache}

\begin{abstract}
This article reports the analysis of a re-semantization and re-categorization process of the lexical pieces parche and chimba. These two words are part of parlache, which is a kind of slang in Colombia. Based on Diccionario de uso de parlache (2015), the results demonstrate that the lexical piece parche acquired new meanings as a noun, prenominal verb and it also forms different phrases. Chimba changes from noun to verb. Parasynthesis is used to create words, verbal phrases and routine formulas.
\end{abstract}

Key words: re-semantization, re-categorization, parche, chimba, parlache.

Recibido: 26-05-2018

Aceptado: 26/12/2018

Este artículo es derivado del proyecto titulado "Cambios léxicos y semánticos del parlache 20062015", financiado por el Comité de Investigaciones de la Universidad de Antioquia, Medellín, Colombia. * Colombiana. Doctora en Filología de la Universidad de Lleida. Profesora titular Universidad de Antioquia, Medellín, Colombia. estela.castaneda@udea.edu.co

*** Colombiano. Magíster en Lingüística de la Universidad de Antioquia. Profesor de Cátedra Universidad de Antioquia, Colombia.ignaciohenaos@gmail.com

**** Colombiano. Doctor en Lingüística de la Universidad de Antioquia. Profesor titular Universidad de Antioquia, Colombia.sergio.lopera@udea.edu.co 


\section{Introducción}

La semántica es una rama de la lingüística que estudia el significado de las palabras. Esta área se encarga de estudiar y analizar los fenómenos de significación de los signos que se presentan a nivel sincrónico o diacrónico en una sociedad determinada (Zecchetto, 2011). Zecchetto (2011) sostiene que el lenguaje humano fue inventado para semantizar la realidad a través de alguna forma codificada, que puede ser a través de las palabras. $Y$ tal vez, sea en la formación de los argots en los que este proceso sea más evidente, porque acude a la trasgresión y al juego, para crearle nuevos sentidos a palabras comunes de la lengua, con el fin de expresar matices de la realidad, que los significados anteriores no pueden referenciar de manera adecuada. Como el objetivo de resemantizar es brindar o agregar un nuevo significado a una palabra ya existente, la resemantización se convierte en uno de los mecanismos más utilizados en los argots, entre ellos el parlache.

En este artículo abordamos el proceso de resemantización de los términos parche y chimba ${ }^{1}$ en el parlache, variedad argótica del español colombiano. Basados en las investigaciones previas sobre el parlache de Castañeda y Henao $(2001,2006)$ y en especial en el Diccionario de uso de parlache (2015), del cual recogemos algunos fragmentos que contextualizan la resemantización de estos dos términos que se han expandido a diferentes lugares y contextos de Colombia, y a través de los medios masivos de comunicación han pasado las fronteras del país.

\section{Marco teórico}

\subsection{Semántica y uso}

Lyons (1997) argumenta que la semántica es el estudio del significado. No obstante, el autor aclara que el significado no solo involucra aspectos nocionales, sino también factores de uso y de contexto; además, se debe tener en cuenta una doble articulación de significados: "Cuando consideramos las palabras (y los sintagmas) como unidades significativas tenemos que tener en cuenta que, por un lado, una única forma se puede combinar con varios

\footnotetext{
Es necesario aclarar que los dos términos que estamos analizando pueden considerarse como préstamos, por cuanto chimba proviene del quechua y parche del francés. Joan Corominas (1998) constata el uso de parche desde 1607 (p. 440), pero no registra el término chimba.
} 
significados y, por otro, un mismo significado puede estar combinado con varias formas de palabras" (Lyons, 1997, p. 75). De acuerdo a lo anterior, el autor propone que el significado de una palabra u oración se determina no solo por este, sino también por su estructura gramatical y esto hace que un elemento lingüístico difiera en significado. Para ilustrar lo anterior, vamos a tomar como ejemplo un par de oraciones del parlache: 1. Son una chimba de viejas; 2 . de viejas son una chimba. En la primera se refiere a mujeres bonitas y en la segunda a mujeres de edad que conservan la belleza. 1. Se dañó el parche con las peladas. 2. con las peladas se dañó el parche. La primera señala que se dañó el programa con las jóvenes y en la segunda indica que con la llegada de las jóvenes al grupo identitario se afectó la relación.

Los ejemplos anteriores ilustran cómo los cambios socioculturales generan la necesidad de transformar el lenguaje para poder dar cuenta de ellos. Al respecto, Ullmann (1972) propone tres posibilidades para nombrar un objeto nuevo o desconocido, o plantear ideas novedosas: 1. "Formar una palabra nueva de elementos existentes, 2. copiar un término de un idioma extranjero o de alguna otra fuente; y finalmente, 3. alterar el significado de una palabra vieja" (p. 237).

En relación con la tercera posibilidad, Casado Velarde (2015, p.15) afirma que "Las enmiendas de mayor entidad desde el punto de vista de la innovación léxico-semántica son, evidentemente, las que redefinen una palabra o locución, o añade alguna nueva acepción"; de la misma manera, Montes (1983) sostiene que la razón principal de cambio léxico obedece a la necesidad que siente el hablante de utilizar palabras motivadas, evocadoras e imaginativas. Asimismo, el Instituto Cervantes (2016) especifica que los sufijos y prefijos son elementos importantes para alterar o crear nuevas palabras, pero aclara que no es lo único, ya que algunos vocablos existentes pueden transformar su significado de manera amplia o restringida. Con respecto al lunfardo, Conde (2011) argumenta que el léxico se incrementa a través de los préstamos, la creación de palabras y la asignación de nuevos significados a las palabras ya existentes. Agrega que el proceso de asignar nuevos significados a las voces corrientes del idioma se denomina creación léxica. Para el autor, esas creaciones de sentido se generan por medio de cuatro procedimientos: Por restricción de significado, por ampliación del mismo, por desplazamiento del significado (metáfora, metonimia y sinécdoque), y por especialización con cambio de género (Conde, 2011, p. 241). 
Para Miguel Breal (sf)², considerado como el creador de la semántica moderna, la ampliación semántica, o sea, la resemantización, tiene causas externas al lenguaje mismo y es fruto del desarrollo de la historia, como ocurrió con los dos términos que venimos analizando; en cambio, la restricción semántica se debe a las condiciones fundamentales del lenguaje (p. 110); además, para él: "Una nueva acepción equivale a una palabra nueva” (p. 129) y, también, una palabra, "por una serie más o menos larga de intermediarios, puede llegar a significar casi lo opuesto de lo que significaba en un principio" (p. 132).

Con relación a la resemantización, Castañeda (2005) argumenta que este factor de cambio semántico permite incorporar al argot piezas léxicas existentes en el lenguaje estándar con un nuevo significado. Además, es uno de los mecanismos más recurrentes para incrementar el léxico argótico, cuyas voces pueden también recategorizarse, es decir, cambiar de categoría gramatical. Por ejemplo y tomando el término chimba, este puede indicar un órgano sexual femenino y se clasifica como sustantivo. También, se convierte en adjetivo y significa bonito, agradable, extraordinario; o bien y con el artículo "la" (la chimba): se convierte en una fórmula de rechazo. En el mismo sentido, Rodríguez (2014) presenta una transferencia o cambio semántico de tipo metafórico, recurso lexicogenésico muy propio de todo argot. El autor presenta como ejemplos de transposición semántica términos relacionados con la droga, voces tabuizadas por la sociedad establecida que los miembros de los grupos marginales "re-nombran", o sea, resemantizan, utilizando palabras de uso común como "viaje” (efecto de la droga) y "hierba” (marihuana). Finalmente, Rodríguez (2014) plantea que esos cambios semánticos se deben a las relaciones estrechas entre los mundos relacionados con la marginación: droga, prostitución y violencia.

\subsection{El parlache}

El parlache es un dialecto social de carácter argótico que crearon los jóvenes de los sectores marginales y populares de Medellín. El impacto de este lenguaje ha sido tal, que, en la vigésima segunda edición del Diccionario de la lengua española, la Real Academia (2001, p. 1683) incluyó la siguiente definición: "parlache. 1. m. Col. Jerga surgida y desarrollada

En la fuente consultada no aparece fecha de publicación, pero en Wikipedia figura como publicado en 1897. 
en los sectores populares y marginados de Medellín, que se ha extendido en otros estratos sociales del país". De hecho, algunos usos que se han encontrado originalmente en el parlache se han extendido a diferentes contextos (prensa, academia, interacciones) y lugares de Colombia, como se ejemplificará más adelante.

El parlache, como una variante del español usado en Colombia, en su proceso de formación, sigue, en términos generales y con pequeñas variantes, los mismos procesos de creación léxica del español general. Así mismo, al ser un dialecto social de carácter argótico, sigue, también, los parámetros de la formación de los argots. Al respecto, Denise Françoise (1976) indica que en estos lenguajes las creaciones puras y simples de significantes son extremadamente raras, porque buscan una motivación, ya sea meramente formal o conceptual (p. 62); así mismo, para la autora: "Los compuestos argóticos son simples calcos de los compuestos corrientes, a menudo paródicos" (p. 63) y “antes que la composición, el argot prefiere las deformaciones de significantes y los desplazamientos semánticos" (p. 64) y, además, los sonidos raros (p. 62).

De igual modo, Castañeda y Henao (2015) argumentan que en el surgimiento del parlache se dan procesos de formación e incorporación léxica, que son fundamentalmente morfológicos y semánticos. En los procesos de formación se presenta la adición, a través de la prefijación, por ejemplo: des -parche: aburrimiento, en el cual el prefijo des- denota una acción opuesta a la de la base nominal (Nueva gramática de la lengua española, 2009, p. 720) y parche, como ambiente agradable: “Qué desparche tan berraco" se usa cuando no hay nada que hacer porque el "hueco está relargo", es decir, los espacios libres entre clase y clase (Nieto, 5 de octubre de 2005). Otro ejemplo de prefijación sería catre-chimba "Que pasa con este calor tan catrechimba (entrada Twitter 5 de febrero, 2017). Al respecto, Castañeda (2005) incluye catre como prefijo: "Su valor es siempre de intensificación, de grado máximo y en este sentido es apreciativo". Para ella, en el parlache, catrechimba significa lo peor, lo más negativo (p. 100). Sin embargo, también puede ser un sustantivo, como se aprecia en otro trino: "Ahí si no se equivoca ese catrechimba" (entrada Twitter, 30 de enero, 2017). Sin embargo y debido al fenómeno de resemantización, los ejemplos previamente mencionados pueden cambiar de significado y es la tarea que se propone a continuación. 


\subsection{Generalidades de parche y chimba}

Para iniciar, es importante anotar que ninguna de las dos voces conserva el significado original que figura en el Diccionario de la Real Academia. En el caso de parche: Del fr. ant. parche 'badana, cuero', y este del lat. Parth ı́ca [pellis] '[cuero] de Partia', trae ocho acepciones y dos locuciones. De estas, solo la 1, la 2 y la 6 se relacionan semánticamente con el parlache, porque las otras acepciones no concuerdan:

1. m. Pedazo de tela, papel, piel, etc., que se pega sobre una cosa, generalmente para tapar un agujero

2. m. Trozo de lienzo u otro material semejante que contiene un medicamento, y se pone sobre una parte determinada del cuerpo.

6. m. Cosa sobrepuesta a otra y como pegada, que desdice de la principal.

En cuanto a chimba, según el DRAE, proviene del quechua: chimba 'de la otra banda'. Y de acuerdo con Luis Cordero (1989): como sustantivo, significa la otra banda, la parte fronteriza; y como adjetivo, lo de la otra banda (p. 29), en general, conceptos relacionados con la orilla de los ríos. También en el DRAE figura chimbo $^{4}$, ba

1. adj. Dicho de una persona: De un pueblo amerindio que habitaba en la región central de los Andes ecuatorianos. U. t. c. s.

2. adj. Perteneciente o relativo a los chimbos. Además, el DRAE trae otros significados sin aparente relación con las anteriores, en zonas demasiado alejadas de la cultura quechua: 1. f. coloq. Hond. Arma de fuego de fabricación artesanal; o chimbo ${ }^{2}$, ba

De or. vasco. 1. adj. fest. bilbaíno (\|natural de Bilbao). U. t. c. s.

2. $\mathrm{m}$.

P.Vasco. Nombre de varias especies de pájaros: alcaudón, colirrojo, curruca, etc.

Como se constata al analizar los diversos sentidos que adquieren parche y chimba en el parlache, especialmente el segundo, es difícil relacionarlos con su significado original. No obstante, estos cambios de significado, según agrega Ullmann (1972), pueden deberse a una infinidad de causas, entre la cuales considera fundamentales: las lingüísticas, las históricas, las sociales, las psicológicas, la influencia extranjera o por cambios en la realidad (p. 225). En este trabajo, al ser sobre un argot, nos interesan los aspectos sociales y psicológicos, porque las causas del surgimiento y desa- 
rrollo del parlache son fundamentalmente sociales y psicológicas, factores imbricados de tal manera que es muy difícil desligarlos de la violencia, marginalidad, narcotráfico, drogadicción, actividades ilegales e impunidad.

En relación con las causas sociales, Ullmann (1972) plantea que las palabras presentan un sentido restringido al pasar de lenguaje ordinario a un nivel especializado (términos de arte, profesión, por ejemplo). De una manera recíproca, los términos que son acogidos del lenguaje de un grupo tienden a aumentar su significado. En cuanto a los factores psicológicos, el autor indica que los cambios de significados están relacionados con el estado de ánimo del hablante y pueden ser superficiales o triviales. Además, Ullmann (1972) enfatiza en el papel que cumplen la emotividad y el tabú en estos cambios de significado: "Una semejanza casual que capta la vista, una asociación humorística que viene al pensamiento, pueden producir una imagen que, por su adecuación o su calidad expresiva, pasará del estilo individual al uso común" (p. 226). En relación con los factores emotivos, Ullmann se basa en Sperber, quien argüía que, al interesarnos intensamente en un tema, tendemos a hablar frecuentemente de él; incluso nos referimos a él cuando tratamos asuntos totalmente diferentes. Los temas estarán siempre presentes en nuestra mente y, por tanto, pueden producirse figuras retóricas tales como símiles, metáforas y analogías. Igualmente, Ullmann (1972) incluye el tabú como parte esencial en el lenguaje, ya que impone una interdicción en algunas personas, animales o cosas sobre sus nombres. Y la palabra tabú tiende a ser abandonada por un sustituto inofensivo: un eufemismo, para llenar el vacío. Estos eufemismos se crean debido al miedo, por delicadeza, decencia y por decoro. En el caso de las dos voces analizadas en este trabajo, se da el proceso contrario. La palabra chimba, como órgano genital femenino, sería vulgar, y su uso reiterado con tantos sentidos corresponde a una reacción frente al lenguaje considerado culto, con el fin de diferenciarse de las consideradas clases altas de la sociedad. En relación con parche, su uso eufemístico solo estaría en la acepción relacionada con una cita amorosa de carácter sexual, como en el siguiente fragmento de un testimonio escrito por un estudiante del grado Once de Medellín. "Se dio para meter un gol en grande, en una prendería, pero el piojo se torció, diciendo que no podía, porque tenía un parche con una pelada". T3

En los ejemplos se incluye la referencia de donde se tomaron, pero es importante aclarar que, cuando son de testimonios anónimos obtenidos hacia 1995, solo se escribe la T; y en los recogidos en 


\subsection{Parche}

Castañeda (2005) sostiene que el primer significado de parche involucra un sitio donde se reúnen los jóvenes a conversar y los drogadictos a consumir narcóticos. En el siguiente ejemplo, tomado de un testimonio (T) recogido en los años 9o, se comprueba su uso. "Como a los diecisiete tenía tremenda moto y estaba trabajando por oficina, ya por lo alto, llegaba al parche en tremendos carros y de vez en cuando nos tiraba una liguita." T. (Estaba trabajando con delincuentes poderosos, por lo general narcotraficantes, y les daba dinero a los amigos). Más adelante fue adquiriendo nuevos sentidos, como:

2. Lugar controlado por una persona o un grupo para realizar ventas informales. "Claro que hay normas, parches que ya tienen dueño y eso hay que respetarlo, son plazas para mercancías específicas y ahí no puede entrar nadie. Tampoco uno puede llegar a vender o hacer lo mismo que los otros porque eso es competir y lo que hay que hacer es trabajar de forma solidaria, ayudarnos entre todos a cuidar el parche". (Agudelo Urrego, 17 de mayo de 2009).

3. Sitio donde se reúnen los jóvenes a festejar. "Jorge me llamó, que si quería caer a un parche que iba a haber de todo, farra, chorro, y todas esas notas". (Castañeda y Henao, 2001, p. 169).

4. También significa cita amorosa, como lo atestigua un joven, ya citado, al criticar a un compañero, quien sacó una excusa para no acompañarlo en una actividad ilícita (robo). "Se dio para meter un gol en grande, en una prendería, pero el piojo se torció, diciendo que no podía, porque tenía un parche con una pelada". T.

5. También designa a un grupo de amigos. Con este sentido la usa el actor Ramiro Meneses, cuando evoca su época de músico: "Entre los años 1980 y 1984, la violencia era otra, menos cruel y descarnada, existían los pistolocos, no los sicarios, no había delincuencia aparente, y caminar para conseguir la música era un placer. Aún en ese entonces no corríamos el riesgo de morir entre las balas o desintegrados por alguna bomba, eso vino después, los torcidos y las motos, al igual que la ropa de marca, dañaron un tercio del parche". (Meneses, 23 de agosto de 2016).

2015-2016, se escribe T (2015). Finalmente, y cuando se basan en conversaciones escuchadas de manera incidental, se escribe CO. 
6. En los últimos años el término se usa para referirse a un grupo criminal de pocas personas, por lo general asociado o dependiente de estructuras mayores. "Al ex fiscal le delata hasta el lenguaje, propio de pandillero de parche con ínfulas de traqueto" (Hernández-Mora, 24 de agosto de 2008). "En la comuna 5 cerca de 20 combos se sirven de pequeños parches de 1o jóvenes a los que les pagan 100.ooo pesos semanales" (Semana, 10 de septiembre de 2016). Quizá el parche (grupo) que tuvo mayor resonancia fue el encargado de ejecutar la acción terrorista contra el ex ministro Fernando Londoño. "Después de la explosión, los compinches de "El Parche de Zuley" comenzaron a comprar motos, carros e inmuebles con el dinero que les pagaron" (Matta Colorado, 2 de septiembre de 2012).

7. Además de los anteriores sentidos, también se utiliza como sinónimo de programa o actividad. "Un parche bacano para los aficionados colombianos al fútbol. En eso se convirtieron los partidos del Real Madrid cuando juega James Rodríguez" (Gómez Marín, 22 de octubre de 2014). Con la misma connotación lo emplea Gonzalo Urquijo, cuando resalta la decisión del director de teatro Farley Velásquez de orientar su vida hacia el arte y no dejarse absorber por los grupos delincuenciales: "Sobrevivir en Medellín a comienzos de los años 80 era una lucha para los jóvenes que carecían de alternativas. Farley no quiso hacer parte del mundo de pandillas; viró su mirada y se refugió en el rock, la poesía y el teatro. Los "parches" con ese grupo de amigos que rechazaron hacer parte de esa Medellín oscura eran ambientados con música de Queen, Black Sabbath o Led Zeppelin" (Urquijo, octubre 2015).

8. Igualmente, adquiere el sentido de ambiente: "En nuestro barrio se vive un parche como ninguno, un parche de mucha locura." T. (2015).

\subsubsection{Recategorización de parche}

Las anteriores acepciones ejemplifican la resemantización del sustantivo parche. A continuación, vamos a presentar nuevos procesos a partir de la recategorización. Al respecto, se puede observar el proceso denominal. Castañeda (2005) argumenta que algunos verbos se forman a partir de los sustantivos y se produce una "verbalización denominal” y agrega que "En el parlache surgió primero la palabra parche y posteriormente el verbo parchar" (p. 72), con varios significados: entre ellos, dar, poner. Por ejemplo, cuando La Mita, el personaje de la tira cómica La Piquiña, 
la echan del lugar donde duerme en la cárcel y tiene que dormir al aire libre. "Qué piedra cuando una piroba se me trastió el cambuche y quedé sana. Entonces me tocó dormir en carretera y pagarle a otra para que me parchara una cobija" (Aricapa, 2004, p. 243). No obstante, su uso más común es como verbo pronominal como puede verse en las siguientes entradas:

1. Situarse, encontrarse. En el relato escrito por un joven estudiante sobre los enfrentamientos en su barrio figura con este sentido: “Transcurrieron los minutos y se comenzó a sentir la tensión, motos, carros de vidrios oscuros y pintas a pie hicieron asustar a los chirretes de la esquina, a las brujildas que se parchaban en las ventanas a divisar lo que ocurría". T. O, en la voz del escritor y exalcalde de Medellín Alonso Salazar, entrevistado por José Guarnizo: “Éramos veinte pelaos que compartíamos esquina en la carrera $85 \mathrm{C}$ con calle 35. Allá está todavía el hueco donde nos parchábamos". (Guarnizo, 9 de agosto de 2010).

2. Tener contactos sexuales. Algunas veces se utiliza sólo para referirse a los besos, otras para el coito. "Oíste mija, ¿y que tu marido te dejó por irse con la mujer del carnicero?, „no puede ser mija!, como dice la ley de Morfy, sabe qué, párchese al carnicero, una librita de carne todos los días" (Posada, 2011, p. 18). "Hoy todos los parceros me están gozando, porque en la farra yo me parché con que reque de vieja". T.

3. Ponerse, por lo general, ropa. "La ropa vieja la regalé y me parché mi buena mecha. Y la suegra cabriada”. (Aricapa, 2004, p. 51).

También se forma el verbo pronominal desparcharse: “Hay un grupo juvenil que se reúnen siempre los sábados. Uno va allá es pa 'desparcharse o a pasarla bueno". T. (2015).

Igualmente se forma el participio parchado, a: sentado, ubicado. Como cuenta Ricardo Aricapa, al referirse al recorrido criminal de La Mita: "Ya se veía parchada en su buena moto y mancada de metra" (Aricapa, 23 de abril de 2007). O el comentario de dos conocidas modelos sobre la experiencia en China: "Somos dos locas parchadas que no teníamos ninguna necesidad de irnos para Asia a lucharla" (Viernes, 22 de enero de 2016, p. 7). Es poco usual, pero también es usado en forma de gerundio, inclusive en un periódico de la Policía Nacional: "Era usual ver en cada una de las esquinas a grupos de jóvenes parchando. 
Se rotaban el vicio de mano en mano, en medio del bullicio de las malas palabra". (Molano, 2014, p. 129).

\subsubsection{Locuciones con el término parche}

Otro de los procesos significativos en el surgimiento del parlache es la creación de locuciones. Con relación a parche, predominan las verbales:

1. abrir del parche. Echar, expulsar. "El pelao se puso a peliar para defender a un parcero; aunque no hubo heridos, al pelao lo hicieron abrir del parche". T.

2. abrirse del parche. Irse del lugar. Salir precipitadamente de un sitio, especialmente del lugar donde se reúnen con regularidad. "Cuando escuché eso, me abrí del parche. Y Diego, el más parcero mío, sólo dijo: Muñoz se une a la guerra, y solo lo miré. Creo que entendió que mi vida no iba marcada por su mismo lápiz, y solo dijo: suerte, parce". (Castañeda y Henao, 2001, p. 52).

3. armar el parche. Organizar la fiesta. Disponer un lugar para una reunión social. "Compramos un chanchito, cajas de cerveza y aguardiente, instalamos el equipo de sonido en la calle y armamos el parche hasta la madrugada". (Salazar, 1990, p. 33).

4. calentar el parche. Poner en evidencia un sitio donde se cometen acciones ilegales o ponerlo en peligro. “Quienes tiran vicio, lo deben consumir a unos cuantos metros del semáforo para no calentar el parche con los policías” (Agudelo Urrego, 17 de mayo de 2009). "Cogió el fierro y dijo: a calentar el parche que esto ya se putió". T.

5. calentarse el parche. Volverse peligroso un lugar o un ambiente. "Ahora el 'parche' se calentó otra vez, como dicen los muchachos". (El Tiempo, 26 de febrero de 2005).

6. coger de parche. Convertir a una persona en objeto de burla o, también, buscarla afanosamente para descargar sobre ella el afecto o los problemas. "Vos sos güevón, con una biblia en la mano, deja eso. Y así todos los días que podían, lo cogían de parche". T. "Al pobre pelao lo cogieron de parche la tía y la mamá, a echarle cantaleta”. CO. (En el Metro, 2 de agosto de 2013).

7. estar solo en el parche. No tener contrincantes. "Los homicidios bajaron un 16\% de un semestre a otro, lo que podía indicar el avance de los grupos paramilitares en la conquista del territorio. Ya estaban solos en el parche". (Aricapa, 2005, pp. 163-64). 
8. irse de parche. Conseguir una relación amorosa de una sola noche. "Esa noche nos fuimos de parche con esas gonoplastas, y como a las 2 A. m., cuando ya estábamos aburridos, nos zafamos de ellas y nos abrimos del parche". T.

9. sacudir del parche. Expulsar. "Quedaban verracos conmigo un tiempo y me sacudian del parche. Sacaban paros y se abrían a camellar solos". (Domínguez, 2015, p. 45).

10. salir por parche. Reunirse un grupo de amigos para realizar alguna actividad por simple disfrute. " 'Villa', uno de los fundadores, junto a Felipe Saldarriaga y Alejandro De La Rosa, decidieron salir por 'parche"'. (Gallego, 7 de julio de 2004, p. 14).

11. ser buen parche. Persona con la que se comparte con facilidad. La emplea con este sentido la actriz colombiana Catalina Sandino: "Kate Winslet es un buen parche. Es una vieja superbonita conmigo que todo el tiempo me está tirando buena vibra". (Sandino, diciembre 2011, p. 97).

Por otro lado, solo encontramos una locución adjetiva con parche: mero parche: Ponderación o elogio de un objeto o de una situación. "Sisas, mero parche de computador" (Lopera, 2016, p. 112). En este caso el adjetivo mero tiene el significado opuesto a la acepción 2 del DRAE: insignificante, sin importancia. Castañeda y Henao, en el Diccionario de uso del parlache la definen a mero, a como intensificador. Puede ser sinónimo del adjetivo gran o adverbio de cantidad: "Mera explosión; claro, mero corto y la casa del cucho echaba humo, se había quemado el equipo de sonido, la estufa, la nevera (...) Mera risa nos dio a todos los parceros por la fechoría antes realizada" (Posada, 2011, p. 56); o significar muy, como en el siguiente ejemplo. "Al instructor del gimnasio, al que íbamos los fines de semana, nos lo encontramos en la discoteca por la noche; tremendo musculoca, en el trabajo mero macho, pero allá, una nena por completo". T. En la Nueva gramática de la lengua española (2009), tomo I, plantean que, en América, si bien mero es adjetivo y no adverbio: "Modifica el grado del adjetivo al que acompaña en expresiones como tantas cosas meras extrañas que he visto (`algo extrañas`, que he visto) (p. 952). También, aunque lo consideran restringido, ubican el uso de mero como grande o voluminoso en Costa Rica y otros países centroamericanos (p. 959), con un significado similar al usado en el parlache. 
También, pudimos encontrar una locución verbal híbrida: open de parch. Esta expresión se utiliza para pedirle a alguien que se retire rápidamente de un lugar. "Si alguien me dice: "Open de parch" le abro la piernas ¿cierto?”. WEB. (Olivera, de mayo de 2012).

\subsection{Chimba}

En la versión digital del Diccionario de la Real Academia las definiciones que presenta de chimba son las siguientes:

“Del quechua chimba 'de la otra banda”'. 1. f. coloq. Hond. Arma de fuego de fabricación artesanal.

chimbo $^{2}$, ba. De or. vasco. 1. adj. fest. bilbaíno (॥ natural de Bilbao). U. t. c. s. 2. m. P. Vasco. Nombre de varias especies de pájaros: alcaudón, colirrojo, curruca, etc.

chimbo $^{4}$, ba

1. adj. Dicho de una persona: De un pueblo amerindio que habitaba en la región central de los Andes ecuatorianos. U. t. c. s.

2. adj. Perteneciente o relativo a los chimbos.

Parte del significado actual y de la resemantización están relacionados con el uso dado desde tiempo atrás en Colombia: órgano genital femenino, vulva; voz registrada por Tobón Betancur en su diccionario Colombianismos desde (1997) [1946], con una definición prejuiciada: "palabra obscena"; también figura en el Nuevo Diccionario de Colombianismos de Haensh y Werner (1993), cuyas tres definiciones siguen siendo actuales, con ejemplos de nuestro corpus: 1. órgano genital de la mujer, vulva. "Según Lozano la jerga se puede construir de diferentes maneras. «Chimba〉, una de las más populares entre los estudiantes, es un claro ejemplo de cómo un vocablo con un contenido específico en el lenguaje (vulva) tiene un significado diferente para ellos: algo bonito, genial, admirable" (Semana, marzo 6 de 2005). 2. Casualidad favorable, buena suerte. "Eh, que cabeceada, metí el culo en esa vuelta y me tocó bailar con la más fea. De chimba no me encanaron". T. 3. Mujer atractiva, como en el desconcierto del periodista de El Colombiano, Samuel Arango: "Cuando mi hijo me dijo sin ningún recato que esa muchacha era una chimba, yo me paralicé. Tardé varios segundos para preguntarle con voz temblorosa qué quería decir. Él me explicó que era una uva, una bacana, una sobrada, una queridura, una chimba" (Arango, 
14 de febrero de 2013). Estos cambios de sentido generan situaciones comunicativas como la que comenta el periodista Samuel Arango. No obstante, el nivel de resemantización de chimba es muy amplio, como se puede constatar a continuación:

1. El concepto de bonito, bueno, atractivo se extendió a diversos ambientes, objetos y personas. "Hizo el comentario del millón, que qué chimba de vuelta. Ahí fue cuando más putería me dio y le respondi, que no, pues tan chimba que casi nos matan". (Peña Restrepo, 2009, p. 42). O como la estudiante de clase alta, cuando habla de su futuro: "Yo me veo soltera, trabajando como comunicadora de un gran hotel y carro chimba". (Johnson, 2000, p. 65).

2. Igualmente, significa mujer. "Se mandaba unas hembras y chimbas, que solo se las he pillado a él". T.

3. Así mismo, chimbo, a, significa persona, situación u objeto falso, de mala calidad. "El premio al excomisionado que desmovilizó a las tenebrosas Auc es el exilio. Si pisa Colombia, lo aguardan cárcel y luego juicio en el tribunal chimbo que impuso la guerrilla". (Hernández-Mora, 3 de julio de 2016). Inclusive, la periodista María Isabel Rueda utiliza la palabra para referirse a la posición del presidente Juan Manuel Santos. "El Presidente ha optado por aplazar la temida reforma tributaria por lo menos hasta el segundo semestre o comienzos del año entrante, con la disculpa chimba de "socializarla" (Rueda, 24 de enero de 2016). En masculino se utiliza sobre todo para calificar los cheques sin fondos. "Vendió la casa y le pagaron con un cheque chimbo y está embalado para pagarle al banco lo que debía”. CO.

4. Por otro lado, chimbo, a, significa tonto o inútil. "Germán Vargas Lleras estuvo este lunes en la mesa de trabajo de Yolanda Ruiz en RCN Radio para dar una entrevista. Mientras transcurría, la periodista le hizo una serie de preguntas de carácter personal, ¿Usted es de los hombres que llora? ¿No llora fácil? ¿Recuerda la última vez que lloró? ¿Su momento más feliz cuál fue? El candidato se limitaba a responder con un "no" o un "no recuerdo", hasta que finalmente manifestó su desagrado por tener que responderlas. "Qué preguntas tan chimbas" le dijo a Yolanda , quien salió a defenderse diciéndole: "Con estas preguntas uno conoce un poco la personalidad, y al final de cuentas, (...) son personas las que toman las decisiones". (Revista Semana, mayo 21 de 2018). 


\subsubsection{Afijos con la palabra chimba}

Por otro lado, el término chimba adquiere significados inesperados cuando se le agregan prefijos y sufijos. En referencia a estos cambios, Montes (1983, p. 38), al referirse a la motivación y creación léxica en el español colombiano, sostiene que "A veces la semántica del nominandum no contiene en sí misma nada que justifique la nueva denominación, que es estrictamente metafórica en cuanto resulta de establecer una comparación entre algún aspecto del nominandum y del proceso con cuya denominación se nombra".

Por ejemplo, con el elemento compositivo retro- crean un nuevo sentido, en este caso no es retroceso, sino un intensificador: "Regresó el cine de Víctor Gaviria, pero independientemente de los festivales, las críticas cinematográficas, los ensayos sobre el cine nacional y demás retrochimbadas, su naturalista película vino a correrle el champú al idioma" (El Espectador, 28 de agosto de 1998, p. 4C). De acuerdo con Castañeda (2005), con el sufijo -ada, en parlache se forman palabras que denotan golpe o agresión, una acción negativa o abundancia ( $\mathrm{p}$. 106). En el caso de chimbada: es una cosa o situación molesta, incómoda, desagradable. Como la situación del personaje de la novela $L a$ ciudad de todos los adioses de César Alzate, expresada en el siguiente fragmento: "Estudiar no quiero, ni chimbadas por el estilo. No, lo mejor es irse abriendo camino por otro lado" (Alzate, 2001, p. 67). Igualmente, se refiere a situaciones u objetos de poco valor o importancia, como el consejo que le da un joven al ladrón que le robó el celular a su novia: "Mi novio le dijo: "no se meta en guiros (problemas) por chimbadas." T. (2015). En el Diccionario de americanismos coordinado por Humberto López Morales (2010), figura como cosa o situación que resulta como no se esperaba.

Así mismo, con el sufijo -mente, denota: tontería, tontamente, inútilmente. Como se evidencia en el testimonio de un soldado, cuando les aconseja a los guerrilleros que sobrevivieron al bombardeo del campamento de Raúl Reyes, entregarse: "En el video aparecen unas tomas oscuras y se escucha a un soldado diciendo: "El barbuchas que queríamos ya lo tenemos hermano, entonces no se hagan matar chimbamente"'. (Semana, 4 de marzo de 2008). Con respecto a -mente, el Diccionario de la Real Academia lo clasifica como elemento compositivo para formar adverbios a partir de adjetivos; sin embargo, nos parece más razonable la explicación de la Nueva gramática de la lengua española (2009), según la cual es 
un sufijo: "mente, ablativo de mens, mentis, que no significaba solamente 'mente, pensamiento', sino también 'ánimo, intención”' (p. 570, 7.14a). Además, según el Instituto Cervantes (2016), quizá sea uno de los adverbios más característicos del español y con una de las propiedades más interesante: "Todos están compuestos por un adjetivo fijado en femenino en singular" y constituye el único procedimiento que los hablantes de español tienen hoy en día para formar adverbios (p. 286).

También, en el proceso de creación léxica, por derivación se aplica la parasíntesis: enchimbado, a con dos sentidos opuestos. Insulto. 1. Tonto. Falto o escaso de entendimiento. "Ese man es un enchimbao, esa pelada hace con él lo que le da la gana." CO. 2. Afortunado. Persona que corre con suerte. "El tipo la mandó a Londres, le dio carro, porque estuvieron en relación durante años. Pero eso no es como que la conoció y al otro día le montó apartamento, no. Muy enchimbada donde le pegue al perro de una vez. Pero eso no es tan fácil, porque los hombres tampoco son bobos". (Celis Albán, 2007, p. 120).

Además, se forman palabras compuestas: carechimba: Insulto, que en condiciones de confianza y familiaridad puede ser forma de tratamiento. “Qué hubo pues, maricas, ¿se van a quedar ahí parados o qué pues, carechimbas?" (Mesa, 2015, p. 51). “Estábamos más nerviosos que un hijueputa, porque ese carechimba estaba escoltado hasta el culo". T.

Igualmente, chimba se usa en diminutivo, por lo general, como intensificador: "Mira a tu mujer, mira lo tuyo... mira como está de chimbita (Domínguez, 2015, p. 145). "Esto por acá se putea (llena) de chimbitas los sábados, se llenan las discotecas, todo el mundo farriando (festejando)". T. (2015).

En relación con el uso del diminutivo -ito, ita como intensificador, Héctor Abad Faciolince (2005), al criticar su excesivo uso por parte de los antioqueños, dice: "Hay diminutivos que voltean por completo el sentido de la palabra: nadie confundirá a una mamá con una mamacita. Las mamacitas suelen ser más carnudas". Mamacita es una mujer muy bonita. Para él, el uso del diminutivo va de la mano con el eufemismo y la exageración; porque, no se refieren necesariamente al tamaño: "Al decir "haceme un favorcito" es como si el sujeto estuviera pidiendo "por favor" dos veces. Así mismo, si alguien pide que lo esperemos "un segundito", estamos seguros de que ese tiempo no será una fracción de segundo". 
También chimba se recategoriza al pasar de sustantivo a verbo: chimbiar", como en el siguiente ejemplo: "Si nos boletea, la lleva; si nos chimbea, lo buscamos gonorreita; ojo pues pirobo que es muy fácil averiguar por dónde vive". (Maldonado, 27 de febrero de 2014). O en el testimonio recogido en un barrio popular en 2015: "Todos esos manes no se pueden ver, porque se quieren dar duro, diciéndose: gonorrea, usted por qué se pasa la vida chimbiándome". T. (2015).

\subsubsection{Otras formas con la palabra chimba}

Algunas preposiciones, artículos y expresiones involucran la palabra chimba. Por ejemplo, con la preposición de: de chimba o de pura chimba indica suerte, estar de buenas. "Se salvaron de chimba porque el cilindro no estalló, si no, les habríamos patasarribiado el carro". (Molano, enero de 2016). O el siguiente comentario escuchado en El Metro: "Nacional ganó la segunda Copa Libertadores de pura chimba".

Con el artículo la: ¡la chimba!, se vuelve una fórmula rutinaria de negación o rechazo. "Un día la encontré fue echada con el mozo en la cama. "No Victor, la chimba, yo no voy a hacer eso". (Domínguez, 2015, p. 76). También, ¡ni chimba!, es una fórmula rutinaria que indica rechazo o negación. “iNi chimba! A mí nadie me va a llevar a ninguna parte, yo no quiero vigilante ni quiero nada”. (Domínguez, 2015, p. 82).

La expresión ¡qué chimba!, es una exclamación admirativa. "Nos tuvieron como 15 días encanados en la finca. Después de eso, volvimos a lo nuestro, a traquetiar, pero no con latas sino con los fierros. Cada uno tenía de a 38, y qué chimba de fierros parce, todos niqueladitos". T. También se usa esta variante, mucho más juguetona: ¡qué chimba papá! denota lo bien que se está en alguna ocasión o situación. "Shakira -por las canciones con contenido que dice hacer-incluirá varios griticos tipo "que chimba papá" en medio de sus conciertos" (El Espectador, 28 de agosto de 1998, p. 4 C).

Quedar o quedarse como una chimba: Desconcertarse, atolondrarse. "Yo llegué y él estaba con una muchacha sentada en los pies y lo estaba besando. Fue algo muy frustrante, pero con mucha decencia y educación me desplacé hacia donde él y lo saludé y se quedó como una chimba, mirándome a los ojos". T. (2015).

En el español de Colombia es común el debilitamiento de la e en los verbos terminados en -ear, como se observa en uno de los dos ejemplos. 
Con el verbo ser y el artículo indeterminado en femenino, indica una valoración positiva: ser una chimba. Una maravilla. Algo muy bueno. "Edwin ya estaba todo chaborro, entonces chunga le dijo: sabe que bacán, el Pérez es una chimba, hágale y verá que se le baja la colinera”. T. "Mi barrio es una chimba". T. (2015); sin embargo, también significa lo opuesto, ser bobo o tonto. "Esta sí es una chimba, se dejó tumbar de ese man en el negocio y perdió todo lo que tenía". CO.

En cambio, con el verbo valer, indica algo sin valor, intrascendente: valer chimba. "Cuando son desconocidos me vale chimba darles bala". (Mesa, 2015, p. 29).

\section{Algunas observaciones y conclusiones}

En este artículo hemos hecho un recorrido de resemantización de los términos parche y chimba que pertenecen al parlache, variedad argótica del español colombiano. Previamente se indicó que se resemantiza cuando a un significante existente en la lengua estándar se le asigna un nuevo sentido. De hecho y con relación a la palabra parche, esta adquiere unos nuevos significados como sustantivo: 1. Lugar controlado por una persona o un grupo para realizar ventas informales, 2. Sitio donde se reúnen los jóvenes a festejar, 3. Cita amorosa, 4. Grupo de amigos, 5. Grupo criminal de pocas personas, 6 . Sinónimo de programa o actividad, 7. Y finalmente adquiere el sentido de ambiente. También, adquiere unos nuevos procesos a partir de la recategorización y sobresale el proceso denominal, especialmente como verbo pronominal en diferentes entradas: situarse, encontrarse, tener contactos sexuales, ponerse (por lo general, ropa), desparcharse. Finalmente, forma un sin número de locuciones, especialmente verbales: abrir del parche, armar el parche, calentar el parche, coger de parche, estar solo en el parche...

En cuanto al término chimba, el nivel de resemantización es muy amplio: 1. Su significado se extendió a cualquier ambiente y objeto, 2. Significado de mujer, y 3. Significado de falso. También y con los sufijos y prefijos, la palabra adquiere otros significados: retro (intensificador: retrochimba), ita (diminutivo: chimb-ita), ada (denota golpe/agresión o bajo valor: chimbada), mente (denota tontería: chimbamente). Por otro lado, la palabra chimba se recategoriza y cambia de sustantivo a verbo (chimbiar). También, se usa la parasíntesis para la creación léxica (enchimbado/a) como tonto o afortunado, y palabras compuestas (carechimba) como in- 
sulto. Finalmente y con el acompañamiento de algunas preposiciones, conjunciones, y artículos se crean fórmulas rutinarias (de pura chimba: de suerte; la chimba: negación; ni chimba: rechazo); con verbos forman locuciones verbales (ser una chimba, quedar como una chimba, valer chimba) y con qué se forman expresiones exclamativas (¡qué chimba!).

A modo de conclusión, es importante precisar que en el término parche hay una cierta continuidad de sentido. Todas las resemantizaciones conservan alguna relación con el sentido general del término. No obstante, y con relación al término chimba, los significados son totalmente ajenos al concepto original y, en su proceso de resemantización, genera significados opuestos o totalmente inesperados, o sea, no hay continuidad de sentido. También, y como se demostró con los ejemplos, el parlache se ha extendido a diferentes contextos colombianos y ya no es exclusivo a grupos marginales de Medellín.

Para terminar este recorrido con parche y chimba, recogemos las palabras del periodista y miembro de la Academia Colombiana de la Lengua Daniel Samper Pizano: "Para que ustedes mismos puedan probar su dominio del parlache, preparé una versión en esta jerga de 'Enriquezca su vocabulario.' Saquen lápiz y traten de resolver el examen. Después, consulten las respuestas correctas. Suerte, llaverías, que esto es la superchimba... (Samper Pizano, 10 de agosto de 2006).

\section{Referencias bibliográficas}

Abad Faciolince, H. (2005). Arte y desastre del diminutivo. Semana.com. Recuperado de http://www.semana.com/opinion/articulo/ arte-desastre-del-diminutivo/74284-3

Agudelo Urrego, A. (17 de mayo de 2009). La república del semáforo. El mundo.com. Recuperado de http://www.elmundo.com/portal/ resultados/detalles/?idx=116539\#.VrUAgPnhDIU

Alzate Vargas, C. (2001). La ciudad de todos los adioses. Medellín: Universidad de Antioquia.

Arango, S. (14 de febrero de 2013). Las viejas palabras. El colombiano. com. Recuperado de http://www.elcolombiano.com/ BancoConocimiento/L/las viejas palabras/las viejas palabras.asp 
Aricapa, R. (2004). Medellín es así. Crónicas y reportajes. Medellín: Ed. Universidad de Antioquia.

(2005). Comuna 13: crónica de una guerra urbana. Medellín: Universidad de Antioquia.

(23 de abril de 2007). Miles de jergas, un solo idioma. El mundo. Disponible en http://www.elmundo.com/portal/resultados/ detalles/?idx=51174\#.VVE8P 1 Oko

Asociación de Academias de la Lengua Española. (2009). Diccionario de americanismos. Lima: Santillana.

Breal, M. (s/f). Ensayo de semántica. Ciencia de las significaciones. Madrid: La España Moderna.

Casado Velarde, M. (2015). La innovación léxica en DEL 2014. Español Actual, 104, julio-diciembre, 9-26.

Castañeda N., L. S. (2005). Caracterización lexicológica y lexicográfica del parlache para la elaboración de un diccionario. Lleida: Universidad de Lleida.

Castañeda N., L., y J. I. Henao S. (2001). El Parlache. Medellín: Centro de Investigaciones y Extensión de la Facultad de Comunicaciones, Universidad de Antioquia.

_ (2006). Diccionario de parlache. Medellín: La Carreta Editores. (2015). Diccionario de uso del parlache. Frankfurt: Peter Lang.

Celis Albán, F. (2007). Confesiones de una puta cara. Bogotá: Intermedio Editores.

Conde, O. (2011). Lunfardo: Un estudio sobre el habla popular de los argentinos. Buenos Aires: Taurus.

Cordero, L. (1989). Diccionario quichua. Quito: Corporación Editora Nacional.

Corominas, J. (1998). Breve diccionario etimológico de la lengua castellana. Madrid: Gredos.

Domínguez, E. (2015). Leidy Tabares la niña que vendía rosas. Bogotá: Intermedio Editores.

El Espectador. (28 de agosto de 1998), ¡Goorsoovio! El Espectador. Santafé de Bogotá: p. 4C.

El Tiempo. (26 de febrero de 2005), Tras fallido pacto entre Farc y 'paras', se reanuda la guerra por el control del Medio Ariari (Meta). 
El tiempo. com. Disponible en http://eltiempo.terra.com.co/ coar/ACC MILITARES/accionesarmadas/ARTICULO-WEBNOTA INTERIOR-1989932.html

Françoise, D. (1976). Los argots. En Martinet, André (Ed.), El lenguaje y los grupos humanos (pp. 53-79). Buenos Aires: Nueva Visión.

Gallego, F. A. (julio de 2004). Los paseos de los 'vesparceros'. De la Urbe. Medellín: Facultad de Comunicaciones, Universidad de Antioquia.

Gómez Marín, J. E. (22 de octubre de 2014). James encara hoy un duro reto. El colombiano. com . Disponible en http://www. elcolombiano.com/BancoConocimiento/J/james encara hoy un duro reto/james encara hoy un duro reto.asp

Guarnizo, J. (9 de agosto de 2010). Las letras que reclaman a Salazar. El colombiano.com . Recuperado de http:// www.elcolombiano.com/historico/las letras que reclaman a salazar-OVEC 99997

Haensch, G. y R. Werner. (1993). Nuevo Diccionario de Americanismos, tomo i. Nuevo Diccionario de Colombianismos. Bogotá: Instituto Caro y Cuervo.

Hernández-Mora, S. (24 de agosto de 2008). El traqueto. El tiempo. com. Recuperado de http://www.eltiempo.com/opinion/ columnistas/saludhernndezmora/el-traqueto 4464120-1

Hernández-Mora, S. (3 de julio de 2016). ¿Y Luis Carlos Restrepo? El tiempo. com. Recuperado de http://www.eltiempo.com/ opinion/columnistas/y-luis-carlos-restrepo-salud-hernandezmora-columnista-el-tiempo/16635679

Instituto Cervantes. (2016). Cocodrilos en el diccionario. Hacia dónde camina el español. Bogotá: Espasa.

Johnson Rodríguez, C. y M, P. Ramírez Gómez. (2000). Influencia del narcotráfico en la apropiación de la moda de los jóvenes de clase alta de Medellín. Medellín: Inédito.

Lopera, S. (2016). Análisis sociolingüístico y pragmático de los cumplidos en una población universitaria de Medellín, Colombia. (Tesis doctoral). Universidad de Antioquia.

Lyons, J. (1997). Semántica lingüística. Una introducción. Barcelona: Paidós. 
Maldonado, J. C. (27 de febrero de 2014). Pasamos la noche en Cazucá y descubrimos cómo opera la limpieza social. El espectador. com. Recuperado de http://www.elespectador.com/noticias/ bogota/pasamos-noche-cazuca-y-descubrimos-operalimpieza-socia-articulo-477668

Matta Colorado, N. (2 de septiembre de 2012). Los infiltrados que descifraron el caso Fernando Londoño. El colombiano. com. Disponible en http://www.elcolombiano.com/ BancoConocimiento/L/los infiltrados que descifraron el caso fernando londono/los infiltrados que descifraron el caso fernando londono.asp

Meneses, R. (23 de agosto de 2016). Confesiones de un punkero. Revista Arcadia.com. Disponible en http://www.revistaarcadia. com/periodismo-cultural---revista-arcadia/articulo/ramiromeneses-rodrigo-d-no-futuro-mutantex-punk-medellinochenta-colombia/53526

Mesa, G. (2015). La cuadra times. Cámara de Medellín. Recuperado de http://www.camaramedellin.com.co/site/Portals/0/ Documentos/2016/LA\%20CUADRA\%20TIME.pdf

Molano, A. (enero de 2016). Entrevista a Isabel Londoño, exdetective que persiguió a las Farc. Soho.com. Disponible en http://www.soho. com.co/vida-soho/articulo/entrevista-la-exdetective-quepersiguio-las-farc-isabel-londono/40139

Molano, J. (2014). El callejón de la puñalada. Palabras justas. Colombia: INPEC

Montes Giraldo, J. J. (1983). Motivación y creación léxica en el español de Colombia. Bogotá: Instituto Caro y Cuervo.

Nieto R, E. (5 de octubre de 2005). El lenguaje universitario: un mundo que hay que entender con diccionario popular a la mano. $E l$ tiempo. com. Disponible en http://eltiempo.terra.com.co/ educ/viau/articulo-web- nota interior-2557546.html

Olivera, S. (5 de mayo de 2012). Sara Olivera@Sextuitierna. Si alguien me dice: "Open de parch" le abro las piernas ¿cierto? Twitter. com. Recuperado de https://twitter.com/Sextuitierna/ status/202292230197739521

Peña Restrepo, L. G. (2009). Diario de un pillo. Medellín: Instituto Tecnológico Metropolitano. 
Posada, R. (2011). Voces del barrio. 2a Edición. Medellín: Impresión Offset.

Real Academia Española y Asociación de Academias de la Lengua Española. (2009). Nueva Gramática de la Lengua Española. Tomo I. Madrid: Espasa Libros.

Real Academia Española. (2001). Diccionario de la Lengua Española. Tomo I y II. 22a Edición. Madrid: Espasa.

Rodríguez González, F. (2014). El lenguaje de la droga en España. En: Zimmermann, Klaus (Ed.), Prácticas y políticas lingüísticas. Nuevas variedades, actitudes y perspectivas. Madrid: Iberoamericana-Vervuert.

Rueda, M. I. (24 de enero de 2016). No deja gobernar. El tiempo. com. Disponible en http://www.eltiempo.com/opinion/ columnistas/no-deja-gobernar-maria-isabel-ruedacolumnista-el-tiempo/16490325

Salazar, A. (1990). No nacimos pa' semilla. Santafé de Bogotá: Cinep.

Sandino, C. en Restrepo Adriana (diciembre de 2011, p. 97). Una extraña en Hollywood. En Bocas: Bogotá.

Samper Pizano, D. (2006). Postre de notas / Parle parlache, parcero. El tiempo.com. Recuperado de http://www.eltiempo.com/ carrusel/2006-08-11/articulo-web-nota interior-3104816.html

Semana. (21 de mayo de 2018). Qué preguntas tan chimbas. Semana. com. Disponible en https://www.semana.com/confidencialessemanacom/articulo/vargas-lleras-responde-a-polemicasobre-preguntas-chimbas/568150

Semana. (6 de marzo de 2005). Fresas con la jerga, parce. Semana. com. Disponible en http://semana.terra.com.co/opencms/ opencms/Semana/articulo.html?id=85061

Semana. (4 de marzo de 2008). Santos muestra video del operativo en territorio ecuatoriano. Semana.com. Recuperado de http:// www.semana.com/noticias/recuadro/santos-muestra-videodel-operativo-territorio-ecuatoriano/130409-3

Semana. (10 de septiembre de 2016). Las pandillas mortales que atemorizan las ciudades. Semana. com. Disponible en http:// www.semana.com/nacion/articulo/pandillas-en-colombia-yposconflicto-violencia-en-las-ciudades/493273 
Tobón Betancourt, J. (1997). Colombianismos. Medellín: Imprenta Departamental.

Ullmann, S. (1972). Semántica: introducción a la ciencia del significado. Madrid: Aguilar.

Urquijo Hoyos, G. (octubre 2015). El último acto: un homenaje a Farley Velásquez. En: Agenda Cultural (pp.18-20). Medellín: Universidad de Antioquia.

Viernes. (22 de enero de 2016). Karen y Sandra dos amigas guerreras. Caracoltv.com. Medellín: 6-7.

Zecchetto, V. (2011). El persistente impulso a resemantizar. Universitas, Revista de Ciencias Sociales y Humanas, 14, 127-142. 